International Journal of Instruction e-ISSN: 1308-1470 • www.e-iji.net

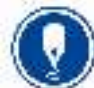

Article submission code: 20200823165611
Received: 23/08/2020

Revision: 24/01/202
July $2021 \bullet$ Vol.14, No.3

p-ISSN: 1694-609X

pp. 787-806

Accepted: 15/02/2021

OnlineFirst: 12/06/2021

\title{
Using Chemistry Concepts Inventory to Identify Alternative Conceptions and Their Persistence in General Chemistry Courses
}

\section{Issa I. Salame}

Asst. Prof., Department of Chemistry and Biochemistry, the City College of New York of the City University of New York, New York City, USA, isalame@ccny.cuny.edu

\section{Pauline Casino}

Department of Chemistry and Biochemistry, the City College of New York of the City University of New York, New York City, USA, pcasino000@citymail.cuny.edu

General Chemistry is a course where students are expected to nurture the development of their fundamental concepts in chemistry. Students begin general chemistry with alternative conceptions about the topics and fragmented knowledge structures. Majority of students who successfully complete the general chemistry course sequence continue to hold onto their alternative conceptions about the topics. The goal of this study is to examine alternative conceptions and their persistence, learning gains, and conceptual change as the result of instruction and completion of a traditional general chemistry course. The Chemistry Concepts Inventory survey was administered as a laboratory activity at the beginning and at the completion of General Chemistry course. The data was collected from 358 participants at a public, urban, and minority serving college and the data was entered into a spreadsheet and analyzed. Our data suggests that normalized learning gains were not substantial after the completion of a general chemistry course taught in the traditional lecture format which may emphasize algorithmic problem-solving and does not address conceptual understanding of the topics. Traditional lecture format in general chemistry falls short of addressing alternative conceptions, causing a conceptual change, and improving conceptual understanding in students. Based on the research, we recommend that General Chemistry teaching and learning strategies need to address alternative conceptions and improve students' conceptual understanding of chemistry key concepts by immersing students in courses where teaching and learning methods are based on research in science education.

Keywords: chemistry education research, alternative conceptions, discrepant events, chemistry learning, chemistry teaching 


\section{INTRODUCTION}

High school students have alternative conceptions about chemistry which stays with them as college students (Sirhan, 2007; Sanger, 2005). Misconceptions or alternative conceptions, conceptions that differ from experts, are of significant importance to measuring conceptual understanding (Caleon \& Subramaniam, 2010). Any concept that student holds and is inconsistent with the established consensus is called a misconception or alternative conception (Smith et al., 1994). Research suggests that students continue to hold onto their alternative conceptions even after instruction in science courses. For example, student hold onto their alternative conceptions when learning about gas particles and they could not accept the fact that gas particles have the same mass as solids (Mayer, 2011). The alternative conceptions stay with students and impede their conceptual understanding of chemistry concepts. Learning new science concepts is influenced by alternative conceptions and is viewed by it (Duit \& Treagust, 1995; Taber, 2015). Students ranging from middle school to doctoral level can possess alternative conceptions about chemistry (Bodner, 1991). Researchers have found that alternative conceptions or misconceptions are resistant to extinction with instruction (Cracolice \& Busby, 2015).

Some research results suggest that high school graduates were not able to fully understand some basic concepts covered in chemistry which include molecular geometry, atomic structure, particulate nature of matter, stoichiometry, chemical bonding, gases, chemical equilibrium, and phase equilibria (Fajardo \& Bacarrisas, 2017). Furthermore, students enrolled in general chemistry have been found to possess a number of alternative conceptions about the topics (Bowen \& Bunce, 1997), which include particulate nature of matter, properties of matter, gases, evaporation, condensation melting, freezing, chemical reactions, dissolving, acids, bases, chemical bonding, thermodynamics, and chemical equilibria. These alternative conceptions can have a negative impact on learning and may persist with students even after instruction (Nakhleh, 1992; Poehnl \& Bogner, 2013). Students hold onto their alternative conceptions and to cause a conceptual change, adequate instruction and active learning are needed (Soneral \& Wyse, 2017). Traditional lecture format does not address conceptual change or promote conceptual understanding of chemistry.

Student achievement depends on three factors: students' mathematical ability which plays a role in students' achievement in general chemistry courses and can a predictor success in these courses (Cooper \& Pearson, 2012), prior knowledge which significantly influences students' achievement (Seery, 2009), and attitude towards the subject matter which can also have an effect on performance and achievement (Bauer, 2008). The three factors can be influenced by teaching method and strategy.

Chemistry Concepts Inventory (CCI) is a test aimed at evaluating students' conceptual understanding of general chemistry concepts (Mulford \& Robinson, 2002). The CCI is a multiple-choice test that is unique in the inclusion of distractors which are related to the alternative conceptions that students may possess. Assessing students' conceptual understanding in science diagnostic tools has been developed and studies in the past four decades (Treagust, 1988; Caleon \& Subramaniam, 2010). CCI validity has been 
established and that it measures fundamental factors related to conceptual understanding of general chemistry topics (Krause et al., 2004). CCI is considered as a type of formative assessment which enables instructors to examine students' knowledge about general chemistry course which otherwise cannot be accomplished at the time of classroom instruction (Shavelson et al., 2008). This type of formative assessment can provide feedback to help instructors gauge their teaching and to check for alternative conceptions that students might hold about the content.

Chemistry Concepts Inventory (CCI) can sample the extent of alternate conceptions and measure students' conceptual understanding of common topics in general chemistry (Mulford \& Robinson, 2002). The purpose of CCI instrument was to measure alternative conceptions that students hold and its changes as a result of instruction and completion of general chemistry course. The CCI includes several topics which include: the particulate nature of matter, molecular geometry, chemical reactions, stoichiometry, law of conservation of mass, phase changes, temperature and heat, gases, liquids and solids, and chemical bonding. Each of the mentioned concepts have been researched either individually or in combination with other concepts. It also relies on the use of drawings for assessment of conceptual understanding beyond the symbolic level. Using CCI to address students' alternative conceptions can improve their problem-solving skills as it improves conceptual understanding (Mulford \& Robinson, 2002; Dickson et al., 2016).

The Chemistry Concept Inventory (CCI) can be easily deployed to a large numbers of students across different courses. The CCI instrument is easy to use, completed in a relatively short period of time and can provide accurate assessment of students conceptual understanding of general chemistry topics. Additionally, CCI can provide valuable information about the students' knowledge when they enter college/university, the learning gains after the completion of a course or sequence of courses, and feedback on the instructional approach. Researcher by Barbera (2013) have examined the validity and reliability of CCI as a psychometric instrument and came to the conclusion that is functions reasonably well as an instrument and that it is appropriate for large-scale assessment of alternative conceptions that students hold.

\section{METHOD}

Our aim of this study is to use the CCI as a survey research instrument to examine alternative conceptions and their persistence, assess learning gains, which is a measure of the improvement in knowledge, and conceptual change as the result of instruction and completion of general chemistry courses. The CCI instrument is comprised of 22 questions that are designed to study conceptual understanding of common general chemistry concepts. The CCI survey was administered as a laboratory activity at the beginning of General Chemistry I and at the completion of the course. The participating students were enrolled in five general chemistry courses taught by five different instructors using traditional lecture format. The survey was administered in accordance with Internal Review Board (IRB). We also obtained permission for authors to use the survey (Mulford \& Robinson, 2002). Students were not allowed to keep a copy of the $\mathrm{CCI}$ and we do not post the survey questions or answers anywhere. Each response was analyzed to determine conceptual knowledge learning gains. 
Our method to answer the research questions was to collect data through CCI questionnaire. Data was collected from students enrolled in general chemistry students at the City College of New York which is a commuter, minority serving, urban, and public university. The students represent a diverse number of majors ranging from science, engineering, liberal arts, and pre-health majors, to post-baccalaureates. A CCI survey research was administered and collected from 358 students $(n=358)$ of the City College of New York.

The data obtained was used to measure students' leaning gains. A learning gain is a measure of magnitude change from pre- to post-test (Bereiter 1963; Pentecost \& Barbera, 3013). A learning gain, measured by comparing pre-test and post-test, is used to gauge the effectiveness of instructional method to address conceptual deficiencies (Bailey et al. 2012). Measuring the change in learning is similar to measuring the rate of the reaction. Researchers in England used Force Concept Inventory (FCI) to determine conceptual understanding and measure learning gain as a result of instruction in a course (Sands et al., 2018).

We also used the data to calculate the normalized learning gains. The equation for normalized learning gain, 〈g (Hake 1998):

$\langle\mathrm{g}\rangle=\left(\frac{\%\langle\text { post }\rangle-\%\langle\text { pre }\rangle}{100 \%-\langle \% \text { pre }\rangle}\right)$

We used the data collected to analyze for alternative conceptions by examining and including the data for incorrect students' responses, their type, and percentages.

\section{Guiding Research Questions}

1. How can CCI be used to identify some of the most common alternative conceptions in general chemistry topics and their persistence?

2. Does traditional lecture format course in general chemistry significantly increase normalized learning gains?

3. Does traditional lecture format in general chemistry address alternative conceptions and lead to conceptual understanding? 


\section{FINDINGS AND DISCUSSION}

Examining Some of the Common Alternative Conceptions in Chemistry

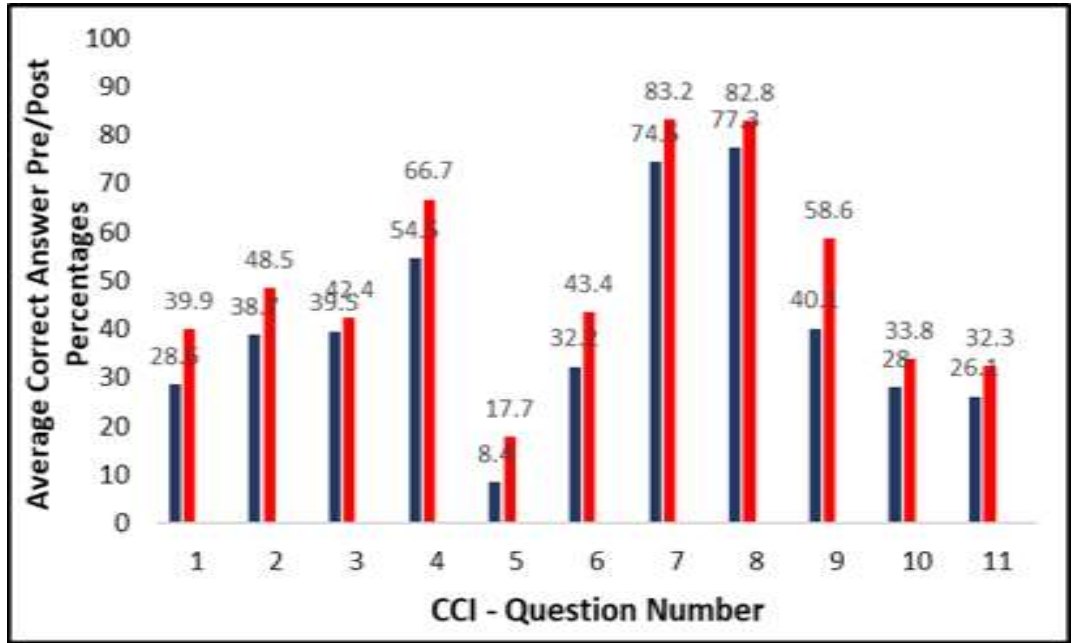

Figure 1

Chemistry concept inventory questions and average correct answer from respondents in pre/post-tests (Questions 1-11).

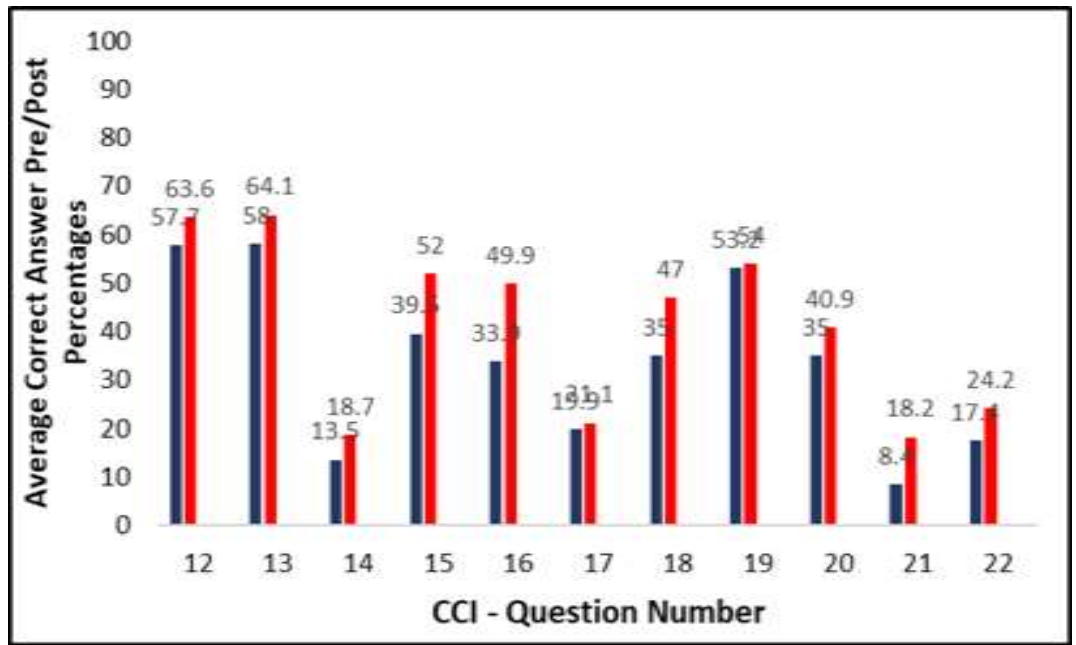

Figure 2

Chemistry concept inventory questions and average correct answer from respondents in pre/post-tests (Questions 12-22). 
Figures 1 and 2 present the results of pre- and post-instruction results of the Chemistry Concepts Inventory. The pre-test results, for some students, are indicative of students' guessing since they have not learned some of the topics yet. The figures also show the data for post-instruction results and they indicate that changes as the result of instruction is not significant.

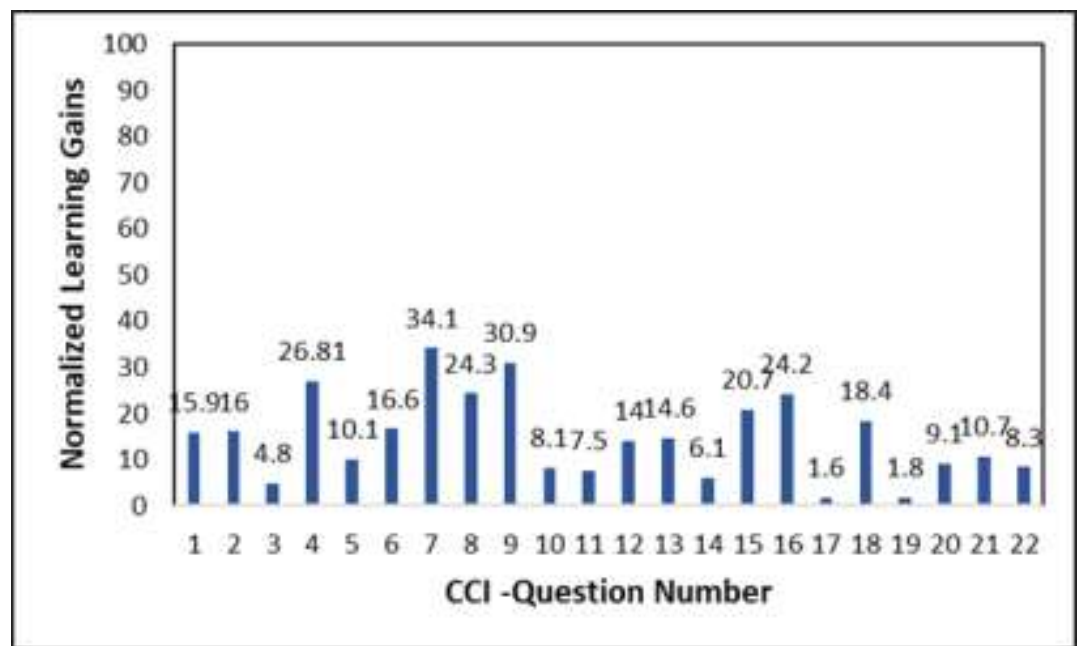

Figure 3

Chemistry concept inventory questions and normalized learning gains.

Learning gains analysis can provide valuable information about a course but not about students' learning of a specific content (Pentecost \& Barbera, 2013). The learning gained obtained for our student population ranged from 1.6 to 34.1 percent as can be seen in Figure 3. The gains were not substantial. The normalized learning gains were lowest for questions related to condensation and water vapor from air, visualization of molecules and elements at the microscopic level, density, scale and size of atoms, temperature and heat, redox reactions and mass, and the distinction between micro and macro worlds.

Research suggests that even after completing general chemistry classes, students still lack conceptual understanding of important topics (Cracolice et al., 2008). Part of the problem is that instructors emphasize symbolic and algorithmic learning of solution concentrations and spend less time exposing students to the microscopic representations (Devetak et al., 2009). In one research study, researchers suggested that students possess deficiencies in abilities to move from the symbolic representational mode of thinking to the different levels of microscopic and macroscopic representational modes (Potgieter et al., 2005). Furthermore, students have difficulties visualizing the particle of matter as part of a solution which limits their conceptual understanding of solutions and concentrations (Gilbert, 2008). 
Another possible explanation for the low learning gains is that in a traditional lecture course format, instructors emphasize problems solving and arithmetic calculations which does not address conceptual understanding. Additionally, in-class examinations focus more on numerical calculations than conceptual problems. This is supported by other research which shows that traditional lecture format emphasizes qualitative approach to problems solving which does not translate to conceptual understanding (Nurenbern \& Pickering, 1987).

Our discussion in the next few paragraphs is focused on a few questions that we identified, based on our data, as the most challenging and persistent alternative conceptions from the CCI.

\section{Phase Changes}

Table 1

Item 3 from the Chemical Concepts Inventory (Mulford \& Robinson, 2002) and percentages of responses for pre and post instruction.

\begin{tabular}{|c|c|c|}
\hline \multicolumn{3}{|c|}{$\begin{array}{l}\text { A glass of cold milk sometimes forms a coat of water on the outside of the glass (Often } \\
\text { referred to as 'sweat'). How does most of the water get there? }\end{array}$} \\
\hline & $\operatorname{Pre}(\%)$ & $\operatorname{Post}(\%)$ \\
\hline $\begin{array}{l}\text { a. Water evaporates from the milk and condenses on the } \\
\text { outside of the glass. }\end{array}$ & 20.1 & 19.7 \\
\hline $\begin{array}{l}\text { b. The glass acts like a semi-permeable membrane and } \\
\text { allows the water to pass, but not the milk. }\end{array}$ & 7.5 & 3.0 \\
\hline Water vapor condenses from the air.* & $39.6 *$ & $42.4 *$ \\
\hline $\begin{array}{l}\text { d. The coldness causes oxygen and hydrogen from the air } \\
\text { combine on the glass forming water. }\end{array}$ & 32.8 & 34.9 \\
\hline
\end{tabular}

For question number 3 , the most common alternative conception the students hold about the formation of water outside a cold milk glass, $32.8 \%$ of students, is that hydrogen and oxygen combine from the air to form water on the glass. Another noteworthy alternative conception, $20.1 \%$ of students, is that water evaporate from the milk and condenses on the outside of the glass. The correct answers are marked with an asterisk. For question number 3 of the CCI, which deals with the condensation of water vapor from air on the outside of a cold glass of milk, the learning gains was calculated and found to be $4.8 \%$, which means that students held on their alternative conceptions in spite of completing a college level general chemistry course. The students' tenacity of holding onto the condensation and phase changes alternative conceptions suggest that they struggle with explaining the problem with applying particle ideas (Osborne \& Cosgrove, 1983). This might be related to the fact development of conceptual understanding of phase changes is closely related to understanding the particulate nature of matter (De Vos \& Verdonk, 1996). 


\section{Chemical Reactions and Stoichiometry}

Table 2

Item 5 from the Chemical Concepts Inventory (Mulford \& Robinson, 2002) and percentages of responses for pre and post instruction.

The diagram represents a mixture of $\mathrm{S}$ atoms and $\mathrm{O}_{2}$ molecules in a closed container.

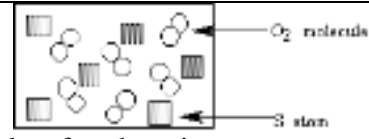

Which diagram shows the results after the mixture reacts as completely as possible according to the equation:

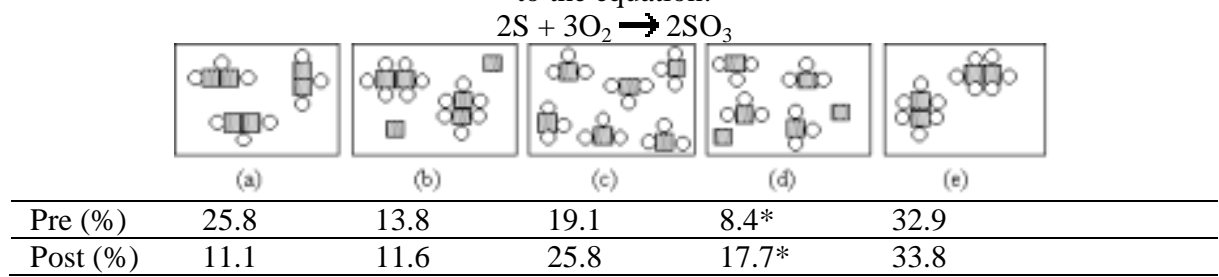

For question number five, the data in table 2 show that the most common misconception is the formation of $\mathrm{S}_{2} \mathrm{O}_{6}$ which is not the product in the equation. This alternative conception persists after the completion of a course in general chemistry. Another alternative conception is the formation of $\mathrm{S}_{2} \mathrm{O}_{3}$, which is also contrary to the reaction provided. The answer provided as $\mathrm{C}$ which is an alternative conception that accounts for the equation but ignores limiting reagent and stoichiometry rules. The students score $8.4 \%$ on the pre-test and $17.7 \%$ on the post-test, and also with a low learning gain of $10.1 \%$. The question deals with conceptual stoichiometry and visualizing molecules and elements involved in a chemical reaction at the microscopic level. The data suggests that they lack the conceptual understanding of molecules at the microscopic level when they enter college. This is supported by research in the field of chemical education that reports that lack of understanding the microscopic representations hinders students' abilities to solve concentration problems that are presented verbally as opposed to bring presented as microscopic representations (de Berg, 2012). The microscopic representation, at the atomic and molecular level, is very challenging for students. Additionally, evidence that students' learning to solve problems algorithmically does not translate to conceptual understanding of key chemistry concepts (Nurenbern \& Pickering, 1987). It is more disheartening to know that the data suggest that after completing a traditional general chemistry course, they still do not have better conceptual understanding of conceptual stoichiometry.

It was found that students after completing general chemistry courses have conceptual understanding ability that lags behind algorithmic problem-solving ability (Nakhleh, 1992). The researchers go even further to state that students who can successfully master algorithmic problem solving, manipulate equations correctly, and achieve success in courses as measured by grades, does not translate to facilitating their conceptual understanding (Nakhleh \& Mitchel, 1993). Students' heavy reliance on algorithmic 
approach to problem-solving has been found to be counterproductive to their learning and success because it does not facilitate conceptual understanding of the concepts (Niaz \& Robinson, 1992). Providing students with the tools to develop conceptual understanding and interrelationships between macroscopic, microscopic, and symbolic level might serve students well in developing conceptual understanding about stoichiometry. Researcher in science education suggests that students have difficulty moving between the three levels of representation and use non-scientific conceptions to provide answers (Adadan \& Savasci, 2012). Lack of understanding the microscopic representations hinders students' abilities to solve concentration problems that are presented verbally as opposed to bring presented as microscopic representations (de Berg, 2012). The microscopic representation, at the atomic and molecular level, is very challenging for students.

\section{Buoyancy and Density}

Table 3

Items 10 and 11 from the Chemical Concepts Inventory (Mulford \& Robinson, 2002) and percentages of responses for pre and post instruction.

10. Two ice cubes are floating in water:

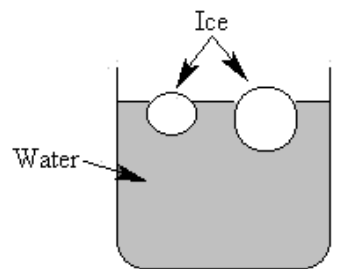

\begin{tabular}{lcc}
\hline After the ice melts, will the water level be: & Pre & Post \\
a. higher? & 58.3 & 53.0 \\
b. lower? & 13.7 & 13.2 \\
c. the same? & $28.0^{*}$ & $33.8^{*}$ \\
\hline 11. What is the reason for your answer to question 10? & Pre & Post \\
a. The weight of water displaced is equal to the weight of & $26.1^{*}$ & $32.3^{*}$ \\
the ice.* & & \\
b. Water is more dense in its solid form (ice). & 11.5 & 10.6 \\
c. Water molecules displace more volume than ice & 8.2 & 8.1 \\
molecules. & & \\
d. The water from the ice melting changes the water level. & 38.8 & 37.4 \\
e. When ice melts, its molecules expand. & 15.4 & 11.6 \\
\hline
\end{tabular}

Questions 10 and 11 of CCI deal with floating ice melting and density. For question 10, the most common alternative conception that student hold about buoyancy and density is that when ice melts the water level would increase. This is supported by the answers provided in question 11, where the students think that water from the ice melting changes the water level. It is noteworthy that $15.4 \%$ of students think that when ice melts the molecules expand and that $11.5 \%$ of the students choose that water is denser in solid form as their answer. The pre- and post-test results for question 10 are $28-33.8 \%$ 
and for question 11 are 26.1-32.3\%. The learning gains for the two questions are 8.1 and $7.5 \%$ which seems to suggest that students held onto their alternative conceptions. Students struggle with learning about density and their struggles and alternative conceptions are tenacious and a challenge for educators to change by relying on traditional instruction in the format of lecture. This is supported by research in science education that describes density as a complex concept and that students face difficulties developing conceptual understanding of it (Dawkins et al., 2008). Density is an abstract concept that requires understanding of mass and volume and ratios to solve which makes it even more challenging. Furthermore, students do not usually think of floating and sinking as forces in action (Heywood \& Parker, 2001), which could hinder their learning of these concepts.

\section{Size and Scale of Atom}

Table 4

Item 14 from the Chemical Concepts Inventory (Mulford \& Robinson, 2002) and percentages of responses for pre and post instruction.

\begin{tabular}{l} 
What is the approximate number of carbon atoms it would take placed next to each other to \\
make a line that would cross this dot: \\
\hline \\
a. 4
\end{tabular}

For question 14, the data in Table 4 show that majority of students do not have a welldeveloped conceptual understanding of atomic size. The majority of students, $65.1 \%$, think that one more of carbon atoms are needed to make a line that crosses a dot. About $21 \%$ in total choose 4 or 200 atoms as a requirement for the dot crossing line which is indicative of thinking about atoms as much larger objects that scientists think they are. It is noteworthy that students scored low on the pre- and post-test of question 14 of the CCI, which has to do with the size and scale of atoms. They scored 13.5 and $18.7 \%$ respectively, and had learning gains of $6.1 \%$ by the time they completed the course. The data suggests that instruction in a traditional lecture format does not address the scale alternative conception that student bring with them to these courses. Other research has found that students struggle with understanding the size of the atom and think it can be seen under a microscope or the size of a point of a needle (Cokelez, 2012). This could be related to the way chemistry courses are taught with emphasis on the symbolic level which does improve conceptual understanding of important topics in chemistry. Even though there are three levels to expressing matter in chemistry, micro, macro, and symbolic, research by Gabel shows that chemistry teaching is predominately carried out at the symbolic level which is ineffective (Gabel, 1999). Conceptual understanding of chemical knowledge can be achieved when the three levels, macroscopic, microscopic, and symbolic, are taught with the interplay between the three levels (Harrison \& Treagust, 2000). 


\section{Heat and Temperature}

For question number 17, which deals with temperature and heat, the average percentages for the pre-test for the participating students are as follow: $1=35.9,2=$ $19.9^{*}, 3=20.4,4=7.4$, and $5=16.4$. For the post test results the averages are; $1=$ $42.9,2=21.1^{*}, 3=17.9,4=7.6$, and $5=10.5$. A significant number of students, 35.9, think that heat added to a system has to do with the boiling point of the substance. Additionally, $16.4 \%$ of students choose the answer that alcohol has a higher specific heat than water. Our results from Figure 3 show that students had a learning gain of $1.6 \%$ and $19.9 \%$ and $21.1 \%$ was the average score on the pre- and post-test, respectively. The data suggests that not only students have alternative conceptions about heat and temperature, they also hold onto these alternative conceptions after the completion of a general chemistry course. Some research findings are consistent with our data and suggest that most students do not have a solid grasp on the difference between heat and temperature and often use the terms interchangeably (Kesidou \& Duit, 1993; Alwan, 2011). Heat and temperature are abstract concepts to learners. Students struggle with alternative conceptions about heat and temperature and find it challenging to develop an understanding of the concepts related to heat and temperature especially thermal equilibrium, specific heat, and heat transfer (Jasien \& Oberem, 2002).

\section{Redox Reactions and Mass}

In question number 19, which has to do with the formation of rust on a nail and how that impacts the mass. the average percentages for the pre-test for the participating students are as follow: $1=10.7,2=53.2 *, 3=13.8,4=8.8$, and $5=13.5$. For the post test results the averages are; $1=11.9,2=54.0 *, 3=9.3,4=8.6$, and $5=16.3$. One of the alternative conceptions from this question is that rust weighs less due to it being flaky in character and thus is lighter. This is contrary to scientific consensus since rust involved the combination of iron and oxygen which results in a higher mass. The learning gain for this question was determined to be $1.8 \%$. We should note that the pre- and post-test results were $53.2 \%$ and $54 \%$, respectively. Majority of the students knew about the mass increase due to oxygen reaction with iron as part of a redox reaction. The data also suggests that most students held onto their alternative conceptions associated with the topic. Most students know that there is a chemical reaction taking place between iron and oxygen, students do not associate the increase of mass with oxygen-iron reaction. A minority of students explained the formation of rust as a chemical reaction that includes oxygen (Driver, 1984). Students hold onto alternative conceptions related to electrochemistry which include the role of concentrations and equilibrium in the electromotive force (Sanger \& Greenbowe, 1997). Using proper laboratory experiments students can lean about electrochemistry, atmospheric corrosion, role of oxygen, and mass changes (Sanders et al., 2018). 


\title{
Solutions, Concentration, and Solubility
}

\section{Table 5}

Items 20 and 21 from the Chemical Concepts Inventory (Mulford \& Robinson, 2002) and percentages of responses for pre and post instruction.

\begin{abstract}
20. Salt is added to water and the mixture is stirred until no more salt dissolves. The salt that does not dissolve is allowed to settle out. What happens to the concentration of salt in solution if water evaporates until the volume of the solution is half the original volume? (Assume temperature remains constant.)
\end{abstract}

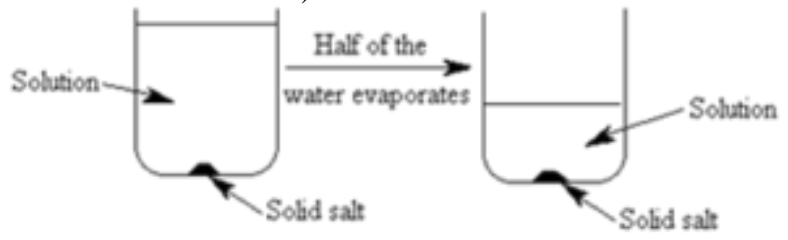

The concentration

a. increases.

b. decreases.

c. stays the same.

The concentration
a. increases.
b. decreases.
51.9
c. stays the same.*
11.9
21. What is the reason for your answer to question 20 ?

$36.2 \quad 41.5$
There is the same amount of salt in less water. $\quad 37.7 \quad 40.1$
b. $\quad$ More solid salt forms.* $\quad 8.8 \quad 18.8$

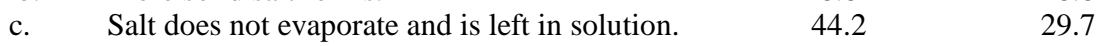
d. There is less water.

$9.3 \quad 11.4$

Pre Post

Questions 20 and 21 have to do with solutions, concentration, and solubility. The major alternative conceptions based on students' answers, $51.9 \%$, is that the amount of salt in a saturated solution will increase after evaporation of some liquid. The reasoning is also problematic in the sense that $37.7 \%$ of students think that concentration of saturated salt increases with evaporation because there is less water and $44.2 \%$ think that concentration change because salt does not evaporate. The learning gains for the questions 20 and 21 are 9.1 and $10.7 \%$, respectively. Our data suggests that students struggle with solutions, concentrations and solubility even after instruction and hold strongly onto their alternative conceptions. Our results are supported by research in the field, where researchers found that students had misconceptions about salt solubility in specific (Barker \& Millar, 1999) and solubility in general (Ebenezer \& Erickson, 1996). The concept of solubility is a challenging and abstract one for the learners because it is often presented at the symbolic level and to some extent on the macroscopic level with little connection to the microscopic level (Johnstone, 1993). Furthermore, recent research on the topic of learning dissolution and precipitation suggests that it would be beneficial to students to connect the macroscopic, symbolic and macroscopic level (Abell \& Bretz, 2019). The issue with emphasizing the symbolic level during instruction is that students fit the microscopic level ideas into their symbolic, equations, and thus 
reinforcing their alternative conceptions, which makes more challenging to cause a conceptual change and improve their understanding of the topic (Kelly et al., 2010).

\section{Atomic and Matter Properties}

Table 6

Item 22 from the Chemical Concepts Inventory (Mulford \& Robinson, 2002) and percentages of responses for pre and post instruction.

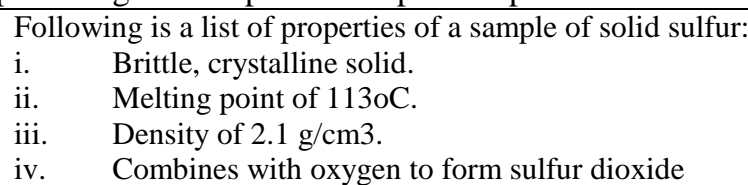

Which, if any, of these properties would be the same for one single atom of sulfur obtained from the sample?

\begin{tabular}{llcc}
\hline & & Pre & Post \\
a. & i and ii only. & 11.1 & 6.6 \\
b. $\quad$ iii and iv only. & 21.3 & 18.7 \\
c. iv only.* & $17.4^{*}$ & $24.2^{*}$ \\
d. All of these properties would be the same. & 39.8 & 46.0 \\
e. & None of these properties would be the same. & 10.3 & 4.5 \\
\hline
\end{tabular}

The properties of a single sulfur atom, question 22, produced learning gains of $8.3 \%$ and pre- and post-test results of 17.4 and $24.2 \%$. The most common alternative conception has to do with the students' thinking that bulk properties and atomic properties are the same and that a single atom can melt just like the bulk metal. The data suggests that students do not differentiate between single atom properties and bulk properties and the relationship between micro and macro world, which is consistent with research in the field of chemistry education research (Ben-Zvi et al., 1986). This is an important part of understanding the particulate nature of matter. Additionally, we think that students' interpretations of microscopic world in terms of atomic and molecular properties may be more challenging for students than instructors think. One of the possible explanations for this alternative conceptions and its persistence is that students rely on reasoning that extend their understanding of matter and its properties at the macroscopic level to that of the microscopic level (Lijnse et al., 1990).

Some argue that students should be involved in inquiry-based learning and research projects early in the curriculum to cause conceptual change (Hestenes, 1995). Science teaching should be taught in a way that students can understand it and appreciate it and should made relevant and meaningful to students (DeBoer, 2000). It is our duty as chemistry educators to make sure that we develop students' competencies to understand the three levels of representations when learning about chemical concepts (Gilbert \& Treagust, 2009).

\section{CONCLUSION}

The data from this research investigation show that for post-instruction results changes in learning gains were not significant. The normalized learning gains were lowest for conceptions related to phase changes, density, scale and size of atoms, temperature and 
heat, redox reactions and mass, and the distinction between micro and macro worlds. One explanation for low learning gains could be the traditional lecture course format, where instructors emphasize problems solving and arithmetic calculations which does not address conceptual understanding. Another possible reason could be attributed to inclass examinations that focus more on numerical calculations than conceptual problems. Additionally, students after completing a General Chemistry course, still held onto alternative conceptions and had deficiencies in their conceptual understanding of numerous topics.

Based on the data obtained, some of the common alternative conceptions students held onto that are related to phase changes and condensation is that hydrogen and oxygen combine from the air to form water on the outside of a cold milk glass and for density is that when ice melts the molecules expand. Other frequent alternative conceptions associated with scale and size of atoms is that it takes a mole of atoms to make a line that crosses a dot and with heat and temperature is that that heat added to a system has to do with the boiling point of the substance. Furthermore, a common alternative conception connected to redox reactions and mass is that rust weighs less than pure iron due to it being flaky in character and thus is lighter.

Instruction in a traditional lecture format does not address the scale alternative conceptions related to the three levels of representations which could be attributed to the fact the chemistry courses are taught with emphasis on the symbolic level while neglecting macroscopic and microscopic representations which are important for conceptual understanding of important topics in chemistry. The microscopic representation is very challenging for students to comprehend and students struggle moving between the three different levels of representations.

General Chemistry teaching and learning strategies need go beyond presenting topics and rely on algorithmic problem solving methods. The course instructors should be cognizant of alternative conceptions so they can be addressed. Furthermore, instructors must work on improving students' learning, achievement and conceptual understanding of chemistry key concepts. This cannot be achieved with a traditional lecture format setting since instructors emphasize problems-solving and arithmetic calculations which does not address alternative conceptions or conceptual understanding. To cause a conceptual change in students, address alternative conceptions they hold, and improve their conceptual understanding of key concepts in chemistry, we recommend that students be involved in inquiry-based learning or an authentic scientific investigation, instructors teach for more emphasis on conceptual understanding than algorithmic problem-solving, instructors work on nurturing students competencies to understand the three levels of representations, and that instructors use teaching methods based on research in science education. 


\section{SUPPORTING INFORMATION}

The complete chemical concepts inventory is available in Journal of Chemical Education Online.

https://www.chemedx.org/JCEDLib/QBank/collection/CQandChP/CQs/ConceptsInvent ory/Concepts_Inventory.html

\section{REFERENCES}

Abell, T.N., \& Bretz, S. L. (2019). Development of the enthalpy and entropy in dissolution and precipitation inventory. Journal of Chemical Education, 96, 1804-1812. https://doi.org/10.1021/acs.jchemed.9b00186

Adadan, E., \& Savasci, F. (2012) An analysis of 16-17-year-old students' understanding of solution chemistry concepts using a two-tier diagnostic instrument. International $\begin{array}{llll}\text { Journal of Science } & \text { Education, } & \text { 34(4), } & \text { 513-544. }\end{array}$ https://doi.org/10.1080/09500693.2011.636084

Alwan, A. A. (2011). Misconception of heat and temperature Among physics students, Procedia Social and Behavioral Sciences, 12, 600-614. https://doi:10.1016/j.sbspro.2011.02.074

Bailey, J.M., Johnson, B., Prather, E.E., \& Slater, T.F. (2012). Development and validation of the star Properties Concept Inventory. International Journal of Science Education, 34(14), 2257-2286. https://doi.org/10.1080/09500693.2011.589869

Barbera, J. (2013). A Psychometric analysis of the Chemical Concepts Inventory. Journal of Chemical Education, 90(5), 546-553. https://doi.org/10.1021/ed3004353

Barker, V., \& Millar, R. (1999). Students' reasoning about chemical reactions: What changes occur during a context-based post-16 chemistry course? International Journal of Science Education, 21, 645-665. https://doi.org/10.1080/095006999290499

Bauer, C. (2008). Attitude towards chemistry: A semantic differential instrument for assessing curriculum impacts. Journal of Chemical Education, 85(10), 1440-1445. https://doi.org/10.1021/ed085p1440

Ben-Zvi, R., Eylon, B. S. \& Silberstein, J. (1986). Is an Atom of Copper Malleable? Journal of Chemical Education, 63(1), 64-66. https://doi.org/10.1021/ed063p64

Bereiter, C. (1963). Some Persisting Dilemmas in the Measurement of Change. In Problems in Measuring Change; Harris. C. Ed.; The University of Wisconsin Press: Madison, WI, pp 3-20.

Bodner, G. M. (1991). I have found you an argument: The conceptual knowledge of beginning chemistry graduate students. Journal of Chemical Education, 68, 385-388. https://doi.org/10.1021/ed068p385 
Bowen, D., \& Bunce, D. M. (1997). Testing for Conceptual Understanding in General Chemistry 1. The Chemical Educator, 2, 1-17.

Caleon, I., \& Subramaniam, R. (2010). Development and application of a three-tier diagnostic test to assess secondary students' understanding of waves. International Journal of Science Education, 32(7), 939-961. https://doi.org/10.1080/09500690902890130

Cokelez, A. (2012). Junior high school students' ideas about the shape and size of the atom. Research in Science Education, 42, 673-686.

Cooper C. \& Pearson P. (2012). A genetically optimized predictive system for success in general chemistry using a diagnostic algebra test. Journal of Science Education and Technology, 21(1), 197-205. Retrieved June 18, 2020 from https://www.learntechlib.org/p/76243/

Cracolice, M. S. \& Busby, B. D. (2015). Preparation for college general chemistry: More than just a matter of content knowledge acquisition. Journal of Chemical Education, 92, 1790-1797. https://doi.org/10.1021/acs.jchemed.5b00146

Cracolice, M. S., Deming, J. C., \& Ehlert, B. (2008). Concept learning versus problem solving: A cognitive difference. Journal of Chemical Education, 85(6), 873. https://doi.org/10.1021/ed085p873

Dawkins, K. R., Dickerson, D. L., McKinney, S. E., \& Butler, S. (2008). Teaching density to middle school students: Preservice science teachers' content knowledge and pedagogical practices. The Clearing House, 82(1), 21-26. https://doi.org/10.3200/TCHS.82.1.21-26

de Berg, K., (2012). A study of first-year chemistry students' understanding of solution concentration at the tertiary level. Chemistry Education Research \& Practice, 13, 8-16. https://doi.org/10.1039/C1RP90056K

De Vos, W., \& Verdonk, A. H. (1996). The particulate nature of matter in science education and in science. Journal of Research in Science Education, 33(6), 657-664. https://doi.org/10.1002/(SICI)1098-2736(199608)33:6

DeBoer, G. (2000). Scientific literacy: Another look at its historical and contemporary meanings and its relationship to science education reform. Journal of Research in Science Teaching, 37(6), 582-601. https://doi.org/10.1002/1098-2736(200008)

Devetak, I., Vogrinc, J., \& Glaar, S.A. (2009). Assessing 16-year-old students' understanding of aqueous solution at submicroscopic level. Research in Science Education, 39(2), 157-179. https://doi.org/10.1007/s11165-007-9077-2

Driver, R. (1984). The pupil as scientist? Open University Press: Milton Keynes. 
Duit, R., \& Treagust, D.F. (1995). Students' conceptions and constructivist teaching approaches. In J.F. Barry \& H.J. Walberg (Eds.), Improving science education (pp. 4669). Chicago, IL: The University of Chicago Press.

Ebenezer, J. V., \& Erickson, L. G. (1996). Chemistry students' conception of solubility: A phenomenograpy. Science Education, 80, 181-201. https://doi.org/10.1002/(SICI)1098-237X(199604)80:2

Fajardo, M. T. M. \& Bacarrisas, P. G. (2017). First-year college students' knowledge in chemistry: Is it adequate? American Journal of Educational Research, 5(10), 10391043. https://doi:10.12691/education-5-10-5

Gabel, Dorothy (1999). Improving teaching and learning through chemistry education research, a look to the future, Journal of Chemical Education, 76(4), 548-554. https://doi.org/10.1021/ed076p548

Gilbert, J. K. (2008), Visualization: An Emergent Field of Practice and Enquiry in Science Education. In J. K.Gilbert, M. Reiner \& M. Nakhleh (ed.), Visualization: Theory and Practice in Science Education, The Netherlands: Springer.

Gilbert, J. K., \& Treagust, D. F., (2009), Macro, Submicro, and Symbolic Representations and the Relationship between them. In J.K. Gilbert \& D.F. Treagust (ed.), Multiple Representations in Chemical Education, The Netherlands: Springer.

Hake, R. R. (1998). Interactive-engagement versus traditional methods: A six-thousandstudent survey of mechanics test data for introductory physics courses. American Journal of Physics, 66(1), 64-74. https://doi.org/10.1119/1.18809

Harrison, A. G., \& Treagust, D. F. (2000). Learning about atoms, molecules, and chemical bonds: A case study of multiple-model use in grade 11 chemistry. Science Education, 84, 352-381. https://doi.org/10.1002/(SICI)1098-237X(200005)84:3

Hestenes, D. (1995). What do graduate oral exams tell us? American Journal of Physics, 63(12), 1069.

Heywood, D., \& Parker, J. (2001). Describing the cognitive landscape in learning and teaching about forces. International Journal of Science Education, 23(11(, 1177-1199. https://doi.org/10.1080/09500690110049051

Jasien, P. G., \& Oberem, G. E. (2002). Understanding of elementary concepts in heat and temperature among college students and K-12 teachers. Journal of Chemical Education, 79, 889-895. https://doi.org/10.1021/ed079p889

Johnstone, A. H. (1993). The development of chemistry teaching: A changing response to changing demand. Journal of Chemical Education, 70(9), 701-705. https://doi.org/10.1021/ed070p701

Kelly, R. M., Barrera, J. H., \& Mohamed, S. C. (2010). An analysis of undergraduate general chemistry students' misconceptions of the submicroscopic level of precipitation 
reactions. Journal of Chemical Education, 87(1), 113-118. https://doi.org/10.1021/ed800011a

Kesidou, S. \& Duit, R. (1993). Students' conceptions of the second law of thermodynamics - An interpretative study. Journal of Research in Science Teaching, 30, 85-106. https://doi.org/10.1002/tea.3660300107

Krause, S., Birk, J., Bauer, R., Jenkins, B., \& Pavelich, M. J. (2004). Development, Testing, and Application of a Chemistry Concept Inventory. 34th ASEE/IEEE Frontiers in Education Conference, October 20 - 23, 2004, Savannah, GA.

Lijnse, F., Licht, P., de Vos, W., \& Waarlo, A. L. (Eds.) (1990). Relating macroscopic phenomena to microscopic particles: A central problem in secondary science education. Centre for Science and Mathematics Education Press, Utrecht, The Netherlands.

Mayer, K. (2011). Addressing Students' Misconceptions about Gases, Mass, and Composition. Journal of Chemical Education, 88(1), 111-115. https://doi.org/10.1021/ed1005085

Mulford, D. R. \& Robinson, W. R. (2002). An Inventory for Alternate Conceptions among First-Semester General Chemistry Students. Journal of Chemical Education, 79(6), 839-844. https://doi.org/10.1021/ed079p739

Nakhleh, M. B. (1992). Why some students don't learn chemistry: Chemical misconceptions. Journal of Chemical Education, 69, 191-196. https://doi.org/10.1021/ed069p191

Nakhleh, M. B., \& Mitchel, R. C. (1993). Concept learning vs problem solving: There is a difference. Journal of Chemical Education, 70(3), 190-192. https://doi.org/10.1021/ed070p190

Niaz, M., \& Robinson, W. R. (1992). From 'Algorithmic Mode' to 'Conceptual Gestalt' in understanding the behavior of gases: an epistemological perspective. Research in Science and Technological Education, 10, 53-64. https://doi.org/10.1080/0263514920100105

Nurenbern, S.C. \& Pickering, M. (1987). Concept learning vs. problem solving: is there a difference? Journal of Chemical Education, 64, 508-510. https://doi.org/10.1021/ed064p508

Osborne, R. and Cosgrove, M. (1983). Children's conceptions of the changes of state of water. Journal of Research in Science Teaching, 20(9), 825-838. https://doi.org/10.1002/tea.3660200905

Pentecost, T. C. \& Barbera, J. (2013). Measuring gains in chemical education: A comparison of two methods. Journal of Chemical Education, 90, 839-845. https://doi.org/10.1021/ed400018v 
Poehnl, S. \& Bogner, F. X. (2013). Cognitive Load and Alternative Conceptions in Learning Genetics: Effects from Provoking Confusion, The Journal of Educational Research, 106:3, 183-196, DOI: 10.1080/00220671.2012.687790

Potgeiter, M., Davidowitz, B., \& Blom, B. (2005). Chemical Concepts Inventory of first year students at two tertiary institutions in South Africa. Proceedings of the Conference of South African Association of Research in Mathematics, Science, and Technology Education, Namibia, pages 664-675.

Sanders, R. W., Crettol, G. L., Brown, J. H., Plummer, P. T., Schendorf, T. M., Oliphant, A., Swithenbank, S. B., Ferrante, R. F., \& Gray, J. P. (2018). Teaching electrochemistry in the general chemistry laboratory through corrosion exercises, $\begin{array}{llll}\text { Journal of Chemical Education, } & \text { 95, } & \text { 842-846. }\end{array}$ https://doi.org/10.1021/acs.jchemed.7b00416

Sands, D., Parkerb, M., Hedgelandb, H., Jordanb, S., \& Galloway, R. (2018). Using concept inventories to measure understanding. Higher Education Pedagogies, 3(1), 173-182. https://doi.org/10.1080/23752696.2018.1433546

Sanger, M. (2005). Evaluating students' conceptual understanding of balanced equations and stoichiometric ratios using particulate drawing. Journal of Chemical Education, 82(1), 131-134. https://doi.org/10.1021/ed082p131

Sanger, M. J., \& Greenbowe, T. J. (1998). Common student misconceptions in electrochemistry: Galvanic, electrolytic, and concentration cells. Journal of Research in Science Teaching, 34(4), 377-398. https://doi.org/10.1002/(SICI)1098-2736(199704)

Seery, M. K. (2009). The role of prior knowledge and student aptitude in undergraduate performance in chemistry: a correlation-prediction study. Chemistry Education Research and Practice, 10(3), 227-232. https://doi.org/10.1039/B914502H

Shavelson, R.J., Yin, Y., Furtak, E.M., Ruiz-Primo, M. A., Ayala, C.C., Young, D.B. Tomita, M. K., Brandon, P. R., \& Pottenger, F.M. (2008). On the role and impact of formative assessment on science inquiry teaching and learning. In J. Coffey, R. Douglas, \& C. Stearns (Eds.). Assessing science learning: Perspectives from research and practice (pp. 21-36). Arlington, VA: National Science Teachers Association Press.

Sirhan, G. (2007). Learning difficulties in chemistry. Journal of Turkish Science Education, 4(2), 1-20.

Smith, J. P., diSessa, A. A., \& Roschelle, J. (1994). Misconceptions reconceived: a constructivist analysis of knowledge in transition. The Journal of the Learning Sciences, 3(2), 115-163. https://doi.org/10.1207/s15327809jls0302_1

Soneral, P. A. G. \& Wyse, S. A. (2017). A SCALE-UP Mock-Up: Comparison of Student Learning Gains in High- and Low-Tech Active-Learning Environments, $C B E-$ Life Sciences Education, 16, 1-15. https://doi.org/10.1187/cbe.16-07-0228 
Taber, K. S. (2009). Progressing Science Education: Constructing the scientific research programe into the contingent nature of learning science. Dordrecht: Springer.

Taber, K. S. (2015). Prior knowledge. In R. Gunstone (Ed.), Encyclopedia of science education (pp. 785-786). Berlin-Heidelberg: Springer-Verlag.

Treagust, D. F. (1988). Development and Use of Diagnostic Tests to Evaluate Students' Misconceptions in Science. International Journal of Science Education, 10(2), 159-169. https://doi.org/10.1080/0950069880100204 